\title{
DRUG INDUCED HYPERPROLACTINEMIA
}

\author{
Wattegama MH¹, Siyambalapitiya $\mathbf{S}^{1}$ \\ ${ }^{1}$ Diabetes and Endocrine unit, North Colombo Teaching Hospital, Ragama.
}

\begin{abstract}
Hyperprolactinemia is one of commonest endocrine abnormalities. It can occur due to various reasons and drugs are one of the commonest reasons. Identifying drugs as the potential cause of elevated prolactin and differentiate it from other possible causes are important in clinical practice. It is important to understand the different classes of drugs that could influence the prolactin release and the potency and the pattern of prolactin elevation with each drug class, to formulate a plan of management for these patients. In the update, we have discussed the types of drugs, their relative potencies of causing hyperprolactinaemia and the steps of management of this clinical entity.

Running title: drug induced hyperprolactinemia
\end{abstract}

Keywords: Hyperprolactinemia, drug induced, antipsychotics.

\section{INTRODUCTION}

Hyperprolactinemia is a condition with elevated prolactin levels in the blood, which may be of physiological, pathological or idiopathic origin. It essentially occurs due to pathological or pharmacological disruption of the hypothalamopituitary dopaminergic pathways. It is one of the commonest endocrine disorders, mostly affecting females. The prevalence of hyperprolactinemia ranges from $0.4 \%$ in an unselected adult population to as high as $9-17 \%$ in women of reproductive age (1). Galactorrhoea and hypogonadotrophic hypogonadism are the usual clinical consequence of hyperprolactinaemia and therefore, females usually present with galactorrhoea and menstrual irregularities such as oligomenorrhoea or amenorrhoea, while males experience erectile dysfunction. Both sexes may experience loss of libido and infertility.

\section{PHYSIOLOGY}

Prolactin (PRL) is a polypeptide with 199 amino acids, which is secreted from the lactotrophic cells of the anterior pituitary. Prolactin is secreted in a pulsatile manner with highest levels occurring during sleep and lowest occurring between 10 a.m to noon. The secreted prolactin gets circulated in different forms, the monomeric (little PRL) with a size of $23 \mathrm{kd}$, dimeric (big PRL) where the size range from 48 - 56 $\mathrm{kd}$ and polymeric forms (big, big PRL) where the size is larger than $1000 \mathrm{kd}$ and monomeric form of prolactin is the most active form. Prolactin is mainly responsible for the milk production during pregnancy and lactation (2). Unlike other trophic hormones of the anterior pituitary, prolactin secretion is not regulated by a negative feedback from the peripheral hormones. Dopamine acts as the primary inhibitory factor for prolactin secretion. Dopamine that gets released from the hypothalamus reaches the anterior pituitary via the hypothalamic-pituitary-portal system and inhibits prolactin secretion by binding to the D2 receptors. Numerous other factors such as fibroblast growth factor, epidermal growth factor, vasoactive intestinal polypeptide (VIP), hypothalamic prolactin releasing peptide (PrRP) and oxytocin also can stimulate the synthesis and release of prolactin. Oestrogen has the ability to stimulate the prolactin gene transcription. In addition to these, serotonin opiates and histamine can also have stimulatory effects on prolactin secretion.

\section{Hyperprolactinemia}

The prolactin levels are maintained less than 25ug/l in women and less than $20 \mathrm{ug} / \mathrm{l}$ in men. However, elevated prolactin levels can be seen in certain physiological conditions. Pregnancy is the commonest physiological condition with hyperprolactinaemia where the levels can go up as high as 10 -fold from the 
baseline. Exercise, meals and chest wall stimulation can also lead to elevated prolactin levels. Although physical and psychological stress can increase prolactin levels, it rarely exceeds $40 \mathrm{ug} / \mathrm{dl}$ (3).

Prolactinomas account for $25-30 \%$ of functioning pituitary tumours. Lesions affecting the hypothalamus and the tumours with compression on pituitary stalk such as non-functioning adenomas, gliomas and craniopharyngiomas can also result in prolactin elevation (4). Mild elevation of prolactin is seen in hypothyroidism due to the stimulatory effect of thyrotrophin releasing hormone on prolactin release (5). Due to the impairment renal clearance, elevated prolactin levels can also be seen in chronic renal failure (6).
Drug-induced hyperprolactinemia

There are several drug classes that can influence the prolactin release leading to hyperprolactinemia and the drugs that influence the action of central nervous system dopamine level and the activity is mainly responsible. It is important to differentiate this cause from pathological causes such as prolactinomas.

Antipsychotic Medication

Anti-psychotic drugs are one of the commonest causes of drug-induced hyperprolactinemia (7). Dopamine antagonist effects of these drugs on D2 receptors of the infundibular hypothalamic pathways and the lactrotrophs are mainly responsible for the hyperprolactinaemia. A study done on 422 patients

Table 1. Major physiologic and pathologic causes of hyperprolactinemia

\begin{tabular}{|c|c|}
\hline Physiologic & $\begin{array}{l}\text { Pregnancy } \\
\text { Breastfeeding } \\
\text { Breast stimulation } \\
\text { Sleep } \\
\text { Stress }\end{array}$ \\
\hline \multicolumn{2}{|l|}{ Pathologic } \\
\hline Pituitary disorders & $\begin{array}{l}\text { Prolactinoma } \\
\text { Mixed pituitary adenoma } \\
\text { Cushing's disease } \\
\text { Acromegaly } \\
\text { Non-secreting adenomas } \\
\text { Pituitary stalk section or tumours } \\
\text { Lymphoid hypophysitis }\end{array}$ \\
\hline CNS disorders & $\begin{array}{l}\text { Tumours } \\
\text { Granulomatous disorders } \\
\text { Vascular disorders } \\
\text { Autoimmune disorders } \\
\text { Hypothalamic tumour and metastasis } \\
\text { Cranial irradiation } \\
\text { Seizures }\end{array}$ \\
\hline Systemic diseases & $\begin{array}{l}\text { Severe hypothyroidism } \\
\text { Chronic renal failure } \\
\text { Polycystic ovary syndrome } \\
\text { Chest wall trauma } \\
\text { Herpes Zoster }\end{array}$ \\
\hline
\end{tabular}

Herpes Zoster 
on antipsychotic medication has shown that the neuroleptic therapy is strongly associated with hyperprolactinemia with a significantly higher prevalence among patients on typical antipsychotics than atypical antipsychotics (8).

\begin{tabular}{|} 
Table 2. Medication causing hyperprolactinemia \\
\hline Antipsychotics \\
Phenothiazines \\
Thioxanthenes \\
Butyrophenones \\
Atypical antipsychotics \\
Antidepressants \\
Tricyclic antidepressants \\
Monoamine oxidase inhibitors \\
Selective serotonin reuptake inhibitors \\
\hline Opiates and Cocaine \\
\hline Antihypertensive Medication \\
Verapamil \\
Methyldopa \\
Reserpine \\
Metoclopramide \\
Domperidone \\
Histamine 2 receptor blockers \\
\hline Estrogens
\end{tabular}

Duration of treatment, age, gender and antipsychotic potency all contribute to the severity of hyperprolactinemia. This side effect is more likely to be seen in adolescents and premenopausal women (8, 9). It has been shown that hyperprolactinemic effect is a dose-related (10). Serotonin is responsible for suckling-induced prolactin release and nocturnal surges. Antipsychotics with serotonergic effects can also stimulate prolactin release via this pathway. However, the prolactin elevation due to serotonin effects are typically milder compared to the dopamine antagonist effects of these drugs. In drug induced hyperprolactinaemia, the prolactin levels are usually $<100 \mathrm{ug} / \mathrm{l}$. However, some drugs such as risperidone and phenothiazines can give rise to a prolactin level exceeding $>200 \mathrm{ug} / \mathrm{l}(10)$.

The older generation, typical antipsychotics are frequently associated with elevated prolactin levels
(11). Rapid elevation of prolactin level is seen after intramuscular injections whereas, with oral drugs, it takes about one week for the levels to rise, which becomes constant thereafter. However, the prolactin levels can get normalized within 48 - 96 hours after discontinuation of these drugs. Among typical antipsychotics, Haloperidol is considered to be the most potent drug causing hyperprolactiaemia (7). With haloperidol, rapid elevation of prolactin to a peak level of about 30-50ng/ml occurs within 6 to 9 days and then reach a plateau and remain constant below a level of $<70 \mathrm{ng} / \mathrm{ml}$ (12). However, a dosedependent increase in prolactin levels has been reported in $40-90 \%$ of patients treated with most of the other phenothiazines (13).

Risperidone that belongs to a newer class of antipsychotics, atypical antipsychotics, can cause even higher levels of prolactin than typical antipsychotics $(12,14)$. Its' dose dependent dopaminergic and serotonin antagonistic actions are mainly responsible for the hyperprolactinaemia with this drug. The prevalence of hyperprolactinemia is so common and it is seen in $70-100 \%$ among patients on risperidone (15). In contrast, olanzapine and quetiapine have lesser effects on prolactin release where the prevalence of hyperprolactinaemia is about 10 to $40 \%$, and with clozapine, it is less than $5 \%$ (7). This discrepancy is mainly due to the difference in the occupancy of the D2 receptors of the pituitary, which is an organ situated outside the blood brain barrier. Risperidone has a higher affinity to D2 receptors in the pituitary, causing a significant hyperprolactinemia (16), whereas the atypical antipsychotics have a weaker affinity for the D2 receptors. It is postulated that the transient binding of these drugs to the D2 receptor and also the agonist as well as antagonist effects at the receptor level are mainly responsible for the weaker effects of these drugs on prolactin release.

\section{Antidepressant medication}

Anti-depressive drugs exert their effect on prolactin release through serotonin pathway. The effects on prolactin are variable and it is not directly related to the therapeutic effect of antidepressants. Data on the incidence of antidepressant-related hyperprolactinemia is scant. Tricyclic antidepressants cause only a mild 
hyperprolactinemia and most studies report no change in prolactin levels $(17,18)$. However, hyperprolactinaemia due to clomipramine is thought to be common (19). Monoamine oxidase inhibitors have shown to act as weak stimuli for prolactin elevation $(18,20)$. Fluoxetine, a selective serotonin reuptake inhibitor, appears to cause a modest elevation of prolactin levels (21). However, the hyperprolactinaemia associated with this class of drugs are generally mild and causes asymptomatic $(22,23)$.

\section{Prokinetics}

Metoclopramide and domperidone are notoriously known for its hyperprolactinemic effect. Both act via dopamine antagonistic mechanism. However, metoclopramide has an additional inhibitory effect on serotonin receptors of the chemoreceptor trigger zone of the central nervous system. Therefore, metoclopramide is considered to be one of the potent stimuli for prolactin release and the levels can be high as 15-fold in patients on chronic metoclopramide therapy (24). It can be associated with amenorrhoea, galactorrhoea, gynaecomastia and impotence (25).

\section{Anti-hypertensive Medication}

Verapamil causes short and long-term increase in basal prolactin secretion. In an outpatient clinic survey among patients taking verapamil, 8.5\% patients reported having a high prolactin level (26). However, the other calcium channel blockers do not seem to have an effect on prolactin secretion (27).

Methyldopa causes moderate hyperprolactinemia by inhibiting the enzyme, aromatic-L-amino aciddecarboxylase, which converts L- dopa to dopamine. With a single dose of alpha-methyldopa (750 to $100 \mathrm{mg}$ ), a rapid rise in prolactin occurs, reaching the peak concentration within 4 to 6 hours. Chronic methyldopa therapy is associated with a three to fourfold rise in the basal prolactin levels. Significantly high serum prolactin levels have also been reported among patients who used to be on centrally acting antihypertensive, reserpine, which is now obsolete in practice.

\section{Opiates}

Opiates can cause both short and long-term increase in prolactin levels and the effect is predominantly through $\mathrm{u}$ receptors. However, the hyperprolactinaemia that we see with group of drugs are very mild $(28,29)$

\section{Estrogens}

The role of estrogens in hyperprolactenemia is controversial. Some studies have shown elevated prolactin in 12 to $30 \%$ of women, where as some have shown no or minimal increase while on oral contraceptive pills (30-33). However, the doses of estrogen that are used in hormone replacement therapy has not demonstrated hyperprolactinemia (22).

\section{Management of drug-induced hyperprolactinemia}

Patients with hyperprolactinaemia need to be evaluated properly and treated accordingly. In a patient with symptomatic hyperprolactinemia, it is imperative to identify medication as a cause at the outset itself. In addition to drug-induced hyperprolactinaemia, mild prolactin elevation can be seen with prolactin-secreting pituitary microadenomas as well as non-functioning pituitary tumours. Therefore, it is important that proper evaluation is done before reassuring the patient.

A careful history with the timing of onset of symptoms and initiation of drugs is of paramount importance.

When drug-induced hyperprolactinaemia is suspected and once the culprit agent is identified, there are several approaches that we can try to differentiate this from other causes of hyperprolactiaemia (22).

1. Discontinuation of the offending drug: the prolactin levels get normalized in 3-4 days after stopping the offending drug. Measuring the prolactin levels 3-4 days of drug withdrawal is the easiest measure to differentiate from other causes of hyperprolactinaemia. However, this should be done with caution especially in patients with antipsychotic 
drugs where the underlying psychosis can get aggravated.

2. Substitution of the offending drug ("switch therapy"): substitution of the offending drug with an alternative drug with a similar action that does not cause hyperprolactinemia is another way or overcoming this problem. Use of atypical antipsychotic agents such as olanzapine, clozapine or quetiapine for traditional antipsychotic medication is a good example. However, this should be attempted with careful consideration after consultation with the attending psychiatrist or the physician (34). If such substitution is not possible, imaging of the pituitary will have to be considered to exclude any mass lesions.

3. When hormone replacement such as estrogen and testosterone for hypogonadism is the reason for hyperprolactinaemia, treatment of the underlying problem and continuation of the offending drug is a challenge. If prevention of osteoporosis is the primary objective of the treatment, alternative medication such as bisphosphonate can be considered in this kind of situations.

\section{Dopamine agonists therapy}

There is a theoretical risk of exacerbating the psychotic symptoms with the use of dopamine antagonist therapy in patients with antipsychotic medication induced hyperprolactinaemia. However, bromocriptine has been used without major problems (22). There is evidence to suggest that cabergoline can be used safely in patients with antipsychotic medication without exacerbating the psychotic symptoms and without having any alteration in antipsychotic effects of these medications (35). However, it is advisable to use these drugs with extreme caution with the close consultation of a psychiatrist only in patients $(36,37)$.

\section{Aripiprazole}

It is a unique atypical antipsychotic agent with partial agonist activity at the $\mathrm{D} 2$ receptor. Recent studies have shown aripiprazole as a potential therapeutic option for drug-induced hyperprolactinemia. Limited data have shown that it can be used as an add-on to the ongoing therapy or as switch therapy, by substituting with the original drug (38).

\section{CONCLUSION:}

Drug-induced hyperprolactinaemia is a common clinical problem and antipsychotic agents are the commonest culprits. If symptomatic, this problem needs to be properly evaluated and treated accordingly to avoid long-term complications related to associated hypogonadism.

\section{REFERENCE:}

1. Majumdar A, Mangal NS. Hyperprolactinemia. Journal of Human Reproductive Science 2013: 6(3): 168-75.

2. Helmed S, Kleinberg D, Ho K. Pituitary physiology and diagnostic evaluation. Williams textbook of endocrinology: $12^{\text {th }}$ Edition 2012: 173-228.

3. Schlechte JA. Prolactinoma. New England Journal of Medicine 2003. 349(21): 2035-2041.

4. Bevan JS, Webster J, Berke CW, Scanlon MF. Dopamine agonists and pituitary tumor shrinkage. Endocrine Review 1992; 13(2): 220240.

5. Snyder PJ, Jacobs LS, Utiger RD, Daughaday WH. Thyroid Hormone Inhibition of the Prolactin Response to Thyrotropin-Releasing Hormone. Journal of Clinical Investigations 1973; 52(9): 2324-2329.

6. Sievertsen GD, Lim VS, Nakawatase C, Fromhman LA. Metabolic clearance and secretion rates of human prolactin in normal subjects and in patients with chronic renal failure. Journal of Clinical Endocrinology and Metabolism 1980; 50(5): 846-852.

7. Inder WJ, Castle D. Antipsychotic-Induced Hyperprolactinaemia. Australian \& New Zealand Journal of Psychiatry 2011; 45(10): 830-837.

8. Montgomery J, Winterbottom E, Jessani M, Kohegyi E, Fulmer J, Seamonds B, et al. Prevalence of hyperprolactinemia in schizophrenia: association with typical and atypical antipsychotic treatment. Journal of Clinical Psychiatry 2004. 65(11): 1491-1498.

9. Madhusoodanan S, Parida S, Jimenez C. Hyperprolactinemia associated with psychotropics-a review. Human Psychopharmacology: Clinical and Experimental 2010; 25(4): 281-297.

10. Smith S, Wheeler MJ, Murray R, O'Keane V. The effects of antipsychotic-induced hyperprolactinaemia on the hypothalamicpituitary-gonadal axis. Journal of Clinical Psychopharmacology 2002; 22(2): 109-114.

11. Haddad PM, Wieck A. Antipsychotic-Induced Hyperprolactinaemia. Drugs 2004; 64(20): 22912314. 
12. Kinon BJ, Gilmore JA, Liu H, Halbreich UM. Prevalence of hyperprolactinemia in schizophrenic patients treated with conventional antipsychotic medications or risperidone. Psychoneuroendocrinology 2003; 28(Suppl 2): 55-68.

13. De Rivera JL, Lal S, Ettigi P, Hontela S, Muller HF, Friesen HG. Effect of acute and chronic neuroleptic therapy on serum prolactin levels in men and women of different age groups. Clinical Endocrinology 1976; 5(3): 273-282.

14. Kleinberg DL, Davis JM, De Costa R, Ban Baelen B, Brecher M. Prolactin levels and adverse events in patients treated with risperidone. Journal of Clinical Psychopharmacology 1999; 19(1): 57-61.

15. Melkersson K. Differences in prolactin elevation and related symptoms of atypical antipsychotics in schizophrenic patients. The Journal of clinical psychiatry 2005; 66(6): 761-767.

16. Arakawa $R$, Okumura $M$, Ito $H$, Takano $A$, Takahashi H, Maeda J, et al. Positron emission tomography measurement of dopamine Dâ,, receptor occupancy in the pituitary and cerebral cortex: relation to antipsychotic-induced hyperprolactinemia. The Journal of clinical psychiatry 2010; 71(9): 1131-1137.

17. Meltzer HY, Piyakalmala S, Schyve P, Fang VS. Lack of effect of tricyclic antidepressants on serum prolactin levels. Psychopharmacology 1977; 51(2): 185-187.

18. Meltzer HY, Fang VS, Tricou BJ, Robertson A. Effect of antidepressants on neuroendocrine axis in humans. Advances in biochemical psychopharmacology 1982; 32: 303-316.

19. Jones RB, Luscombe DK, Groom GV. Plasma prolactin concentrations in normal subjects and depressive patients following oral clomipramine. Postgraduate Medical Journal 1977; 53(Suppl 4): 166-171.

20. Price LH, Charney DS, Heninger GR. Effects of tranylcypromine treatment on neuroendocrine, behavioral, and autonomic responses to tryptophan in depressed patients. Life Sciences 1985; 37(9): 809-818.

21. Papakostas GI, Miller KK, Peterson T, Sklarsky KG, Hilliker SE, Klibanski A, et al. Serum prolactin levels among outpatients with major depressive disorder during the acute phase of treatment with fluoxetine. The Journal of clinical psychiatry 2006; 67(6): 952-957.

22. Molitch ME. Medication-induced hyperprolactinemia. Mayo Clinic Proceedings 2005; 80(8): 1050-1057.

23. Wieck A, Haddad P. Hyperprolactinaemia caused by antipsychotic drugs. This common side effect needs more attention. British Medical Journal 2002. 324: 250-252.
24. Tamagna EL, Lane W, Hershman JM, Carlson HE, Sturdevant RA, Poland RE, Rubin RT. Effect of chronic metoclopramide therapy on serum pituitary hormone concentrations. Hormone Research 1979; 11(4): 161-169.

25. Aono T, Shioji T, Kinugasa T, Onishi T, Kurachi K. Clinical and endocrinological analyses of patients with galactorrhea and menstrual disorders due to sulpiride or metoclopramide. Journal of Clinical Endocrinology and Metabolism 1978; 47(3): 675-680.

26. Romeo JH, Dombrowski R, Kwak YS, Fuehrer S, Aron DC. Hyperprolactinaemia and verapamil: prevalence and potential association with hypogonadism in men. Clinical Endocrinology (Oxf) 1996; 45(5): 571-575.

27. Kelley SR, Kamal TJ, Molitch ME. Mechanism of verapamil calcium channel blockade-induced hyperprolactinemia. American Journal of Physiology 1996; 270(1 Pt 1): E96-100.

28. Zis AP, Haskett RF, Albala AA, Carroll BJ. Morphine inhibits cortisol and stimulates prolactin secretion in man. Psychoneuroendocrinology 1984; 9(4): 423-427.

29. Mendelson JH, Mell NK, Teoh SK, Ellingboe J, Cochin J. Cocaine effects on pulsatile secretion of anterior pituitary, gonadal, and adrenal hormones. Journal of Clinical Endocrinology and Metabolism 1989; 69(6): 1256-1260.

30. Reyniak JV, Wenof M, Aubert JM, Stangel JJ. Incidence of Hyperprolactinemia During Oral Contraceptive Therapy. Obstetrics \& Gynecology 1980; 55(1): 8-11.

31. Luciano AA, Sherman BM, Chapler FK, Hauser KS, Wallace RB. Hyperprolactinemia and contraception: a prospective study. Obstetrics and Gynecology 1985; 65(4): 506-510.

32. Davis JR, Selby C, and Jeffcoate JW. Oral contraceptive agents do not affect serum prolactin in normal women. Clinical Endocrinology (Oxf)1984; 20(4): 427-434.

33. Hwang PL, Ng CS, Cheong ST. Effect of oral contraceptives on serum prolactin: a longitudinal study in 126 normal premenopausal women. Clinical Endocrinology (Oxf) 1986; 24(2): 127133.

34. Kinon BJ, Basson BR, Gilmore JA, Malcolm S, Stauffer VL. Strategies for switching from conventional antipsychotic drugs or risperidone to olanzapine. The Journal of Clinical Psychiatry 2000; 61(11): 833-840.

35. Coronas R1, Cobo J, Giménez-Palop 0, Ortega E, Márquez M. Safety of cabergoline in the management of pituitary prolactin-induced symptoms with patients treated with atypical neuroleptics. Current Drug Safety 2012; 7(2): 9298. 
36. Dorevitch AR, Aronzon R, Stark M, Psychotic exacerbation attributed to low-dose bromocriptine treatment of galactorrhea and hyperprolactinemia. Acta Obstetrica et Gynecologica Scandinavica 1991; 70(4-5): 375376.

37. Miller KK. Management of hyperprolactinemia in patients receiving antipsychotics. CNS Spectrums 2004; 9 (8 Suppl 7): 28-32.

38. De Berardis D, Fornaro M, Serroni N, Marini S, Piersanthi M, Cavuto $M$, et al., Treatment of antipsychotic-induced hyperprolactinemia: an update on the role of the dopaminergic receptors D2 partial agonist aripiprazole. Recent Patients on Endocrine, Metabolic and Immune Drug Discovery 2014; 8(1): 30-37 